\title{
PALEORADIOLOGIA: ESTUDIO IMAGENOLOGICO DEL NIÑO DEL CERRO EL PLOMO
}

Drs. Alvaro Sanhueza $S^{(1)}$, Lizbet Pérez $M^{(1)}$, Jorge Díaz $J^{(1)}$, David Busel $M^{(1)}$, MSC Mario Castro (2), TM Alejandro Pierola $T^{(1)}$.

1. Centro de Imagenología del Hospital Clínico Universidad de Chile.

2. Facultad de Medicina y Facultad de Ciencias Sociales de la Universidad de Chile. Subdirección de Museos, Dirección de Bibliotecas, Archivos y Museos.

\begin{abstract}
Objectives: To describe the imagenologic findings of the "Niño del Cerro El Plomo» mummy. To check preservation status and look for clues of disease and make death related findings using a multisistemic evaluation and describe anthropometric features. Methods: A whole body multislice CT scan was done, followed by multiplanar reconstructions. We did an exhaustive analysis of internal organs. Results: The mummy is in a fetal position. The musculoskeletal system is well preserved. The age was estimated by the growth patterns of the teeth, it was 8 years old. The internal organs are distinguishible but with different degrees of shrinkage and volume loss. The best preserved organ is the central nervous system. The oropharinx, esophagus and stomach are partially filled with contents. The subcutaneous fat layer thickness, bone mineralization and development suggest normal nutritional status. There is no evidence of traumatic injuries related to death. Conclusions: Multislice CT help us to determinate the general conditions of the mummy and the state of the internal organs, avoiding damaging its integrity. We generated important anthropologic and paleopathologic data that wasn't available before.
\end{abstract}

Key words: Mummy, Paleoradiology.

Resumen: Se describen los hallazgos imagenológicos de la momia del Niño del Cerro El Plomo, un Inca de aproximadamente 8 años, momificado en forma natural, que ha estado congelado alrededor 500 años, y que fue encontrado en 1954. Se realizó TC helicoidal multicorte y se obtuvieron recons-trucciones multiplanares orientadas para estudio dirigido de los distintos segmentos corporales. Evaluamos el estado de preservación de todos sus sistemas, así como las características

Sanhueza A. Paleoradiología: Estudio imagenológico del niño del cerro El Plomo. Rev Chil Radiol 2005; 11: 184-190.

Correspondencia: Dr. Alvaro Sanhueza $S$.

E-mail:sanhuezasegovia@hotmail.com físicas. Buscamos en forma dirigida la presencia de enfermedades y hallazgos relacionados con su muerte y estimamos su edad odontológica y ósea. La momia se encuentra en posición fetal y su esqueleto se encuentra en excelente estado de conservación, lo que se asocia a adecuada preservación del sistema muscular y del celular subcutáneo, que impresionan normales tanto en volumen como en morfología, lo cual sugiere un adecuado estado nutricional. Llamó la atención la presencia de imágenes, que impresionan ser linfonodos axilares bilaterales. Todos los órganos internos presentan grados variables de disminución de volumen por deshidratación, siendo el sistema nervioso central el mejor conservado. Fue posible identificar y caracterizar los órganos torácicos y en menor grado los abdominales. La orofaringe, el esófago y estómago presentan moderada cantidad de contenido alimentario. Fue posible observar también la presencia de material que impresiona como fecal en el recto y región interglútea, lo que hace plantear la posibilidad de que el niño hubiese vomitado y defecado en los momentos previos a su muerte. No se identificaron lesiones traumáticas en relación a su muerte. El estudio imagenológico permitió caracterizar el estado de la momia en forma no invasiva, preservando su integridad. La TC helicoidal multicorte permitió tal información, gracias a su capacidad multiplanar y mayor resolución espacial $y$ de contraste.

Palabras clave: Momia, Paleorradiología.

\section{Introducción}

La momia del cerro El Plomo es un niño de aproximadamente 8 años, sacrificado en honor al dios inca Inti, en el Cerro El Plomo a 5.420 metros de altura, en los Andes chilenos. Momificado en forma natural, ha estado congelado por alrededor de 500 años. Fue descubierto en 1954 y actualmente se encuentra preservado en el Museo de Historia Natural, en una cámara de refrigeración a menos 5 grados Celsius (Figura 1). 


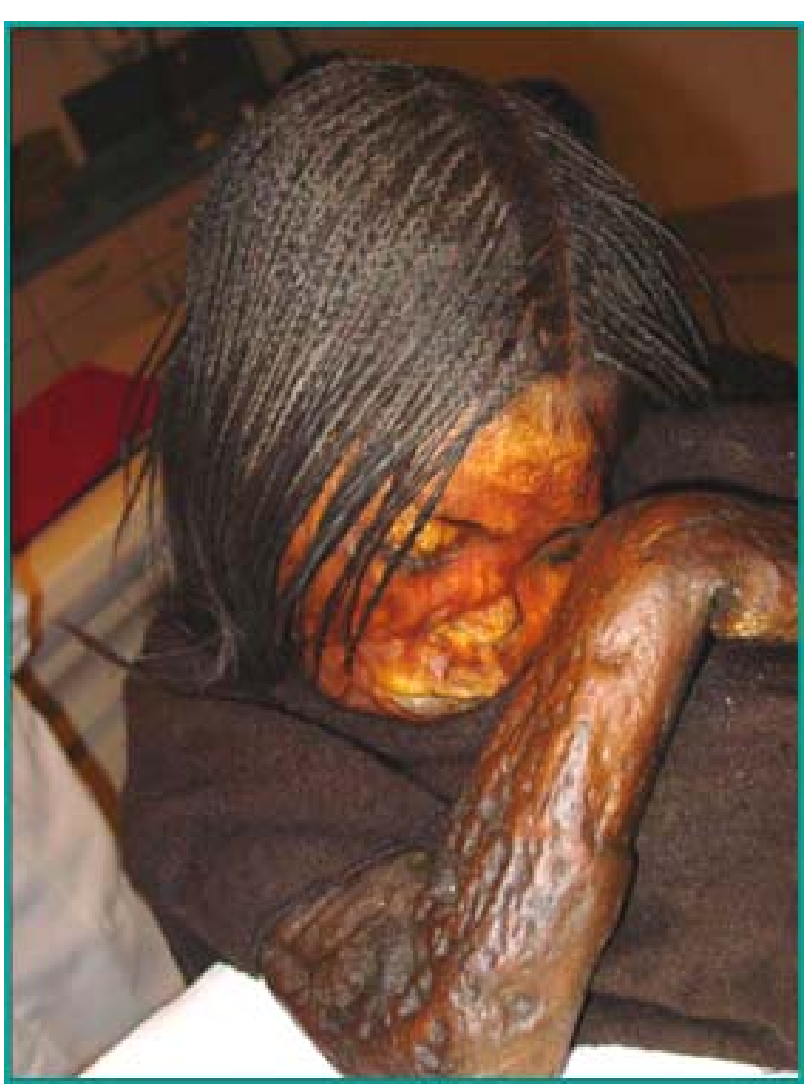

Figura 1. La momia del "Niño del cerro El Plomo» en el Centro de Imagenología.

Una momia es un cadáver en el que se han preservado parcial o totalmente los tejidos blandos, músculos, cabellos, piel, etc., a través del tiempo. La palabra momia deriva del árabe «mumiya», betún de embalsamar cadáveres y ésta del persa mum, cera. Con el transcurso del tiempo la palabra momia pasó a designar a los cuerpos tratados con dichas sustancias, perdiendo su significado original.

Existen tres tipos de momificación: a) Natural: Depende exclusivamente de factores medioambientales. b) Natural intencional: Intervienen tanto factores medioambientales como signos de actividad humana que denotan la intención de conservar el cuerpo. c) Artificial: En la que la conservación del cuerpo es más compleja, debido a prácticas mortuorias y rituales que requieren un gasto de energía adicional de la sociedad, que se especializa en la preparación y tratamiento de los cadáveres.

La paleoradiología es la aplicación de las distintas modalidades de estudio, por imagen aplicadas en medicina para la evaluación de antiguos restos esqueléticos humanos o de animales. Esta disciplina puede ser dividida en dos ramas, la primera la «Paleoradiología anatómica» sólo busca determinar las características morfológicas de los restos esqueléticos y fósiles de homínidos, sin la participación del médico radiólogo en su evaluación.
La segunda rama es la «Paleoradiología Diagnóstica", en la que se tiene el propósito de identificar la presencia de enfermedades en los restos estudiados. Esta modalidad debe ser supervisada por radiólogos, ya que son quienes tienen el entrenamiento necesario para diagnosticar enfermedades a través de las imágenes.

\section{Objetivos}

Describir los hallazgos imagenológicos en tomografía computada multicorte (TC-M) de la momia del niño del cerro El Plomo.

Evaluar el estado de preservación de todos sus sistemas de órganos en forma detallada, así como sus características físicas.

Buscar en forma dirigida la presencia de enfermedades y hallazgos relacionados con el momento de su muerte.

Estimar la edad en base al desarrollo dental mediante reconstrucciones de TC-M, y a la radiografía de mano obtenida en 1954.

\section{Metodología}

El 7 de septiembre de 2003 se realizó una TC$\mathrm{M}$ a la momia del niño del cerro El Plomo en un tomógrafo Siemens Somatom Emotion Duo del Centro de Imagenología del Hospital Clínico Universidad de Chile. El estudio se realizó en una sola sesión mediante adquisición volumétrica, con colimación de $3 \mathrm{~mm}, 130 \mathrm{kV}$ y $137 \mathrm{mAs}$. Un radiólogo y personal del Museo de Historia Natural supervisaron el procedimiento. Para los fines antes mencionados, la momia fue transportada desde el Museo de Historia Natural, hasta nuestro hospital en cámara refrigerada. El traslado se realizó con todos los cuidados pertinentes para no dañar ningún tejido, a una temperatura y humedad óptimas para los requerimientos de su conservación.

Posteriormente se obtuvieron reconstrucciones multiplanares convencionales, multiplanares curvas orientadas según el segmento corporal a estudiar y multiplanares MIP (Major Intensity Projection); además se realizaron reconstrucciones volumétricas SSD (Shadow Surface Display) y VRT (Volume Rendering Technique).

Se tomaron muestras por punción de tejido hepático, cresta ilíaca y calcáneo guiadas por TC.

Una vez procesadas las imágenes y obtenidas las reconstrucciones, un radiólogo y dos residentes de radiología, analizaron detalladamente la información en un sistema PACS IMPAX de Agfa.

Un radiólogo pediatra estimó la edad ósea a través de la radiografía de mano obtenida en 1954. El diagnóstico de edad odontológica fue realizado por un odontólogo dedicado a la radiología, en base a la TC-M. 

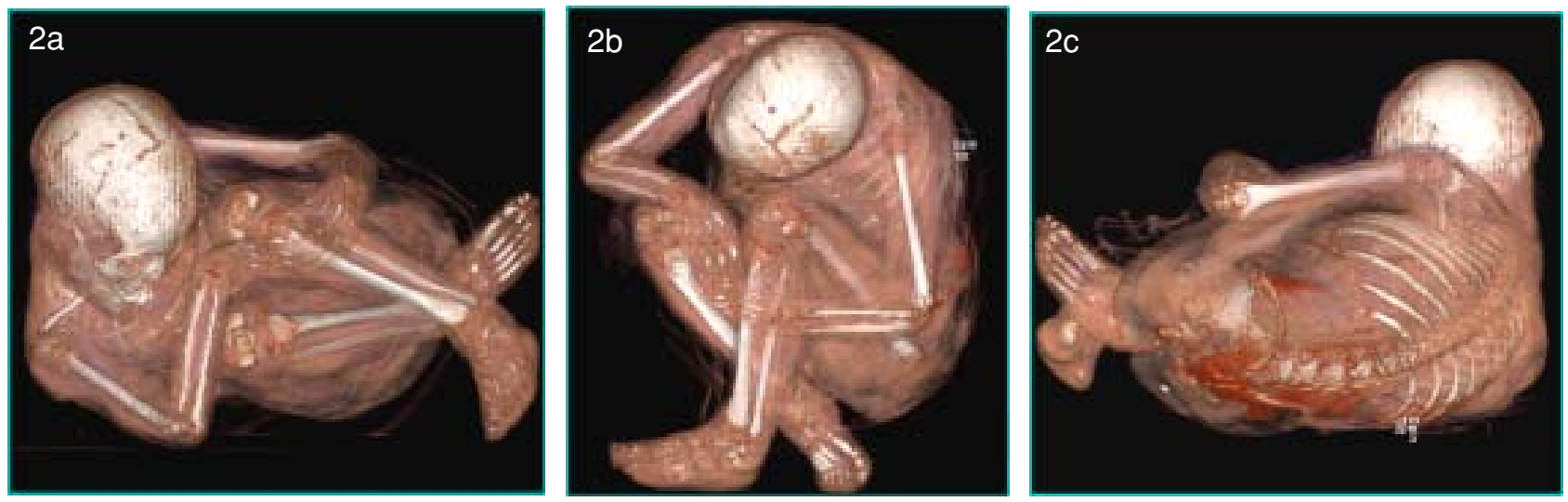

Figura 2 a-c. Reconstrucción VRT de cuerpo entero. Visión frontal (a), superior (b) y posterior (c).
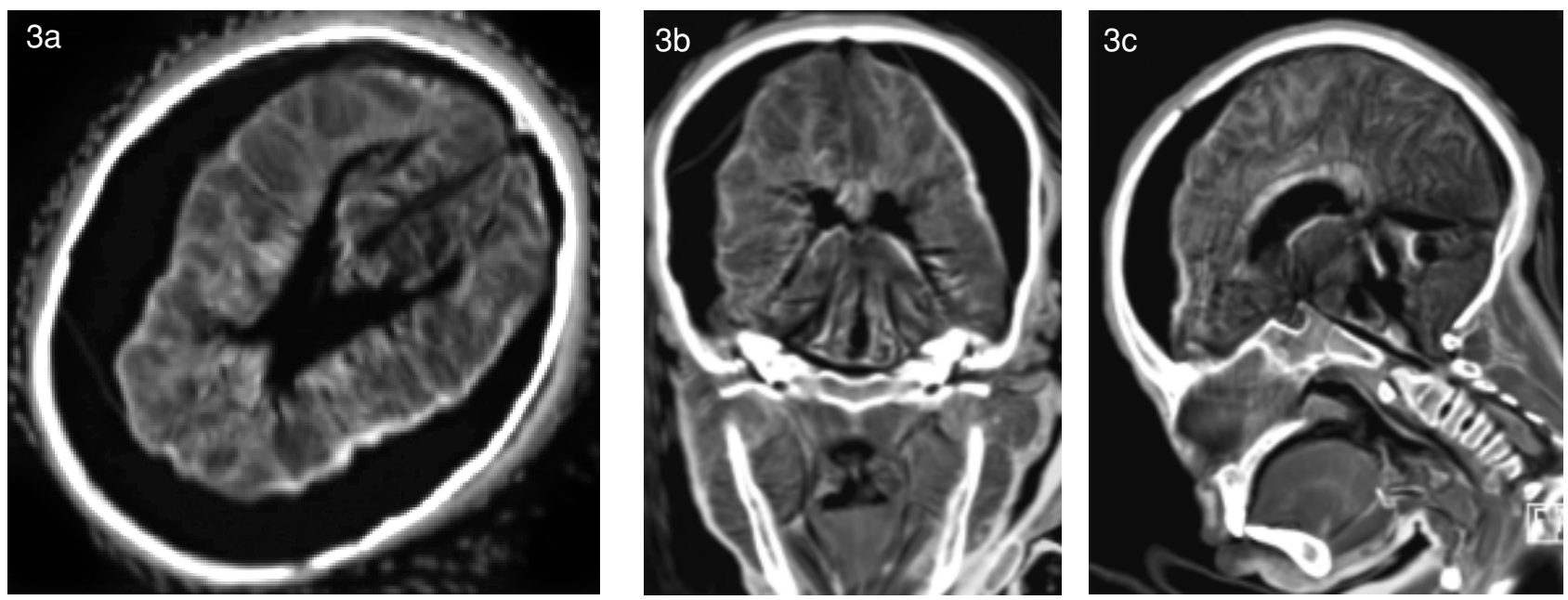

Figura 3 a-c. Reconstrucciones axiales (a), coronales (b) y sagitales (c) del encéfalo.

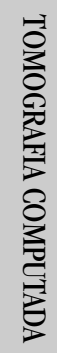

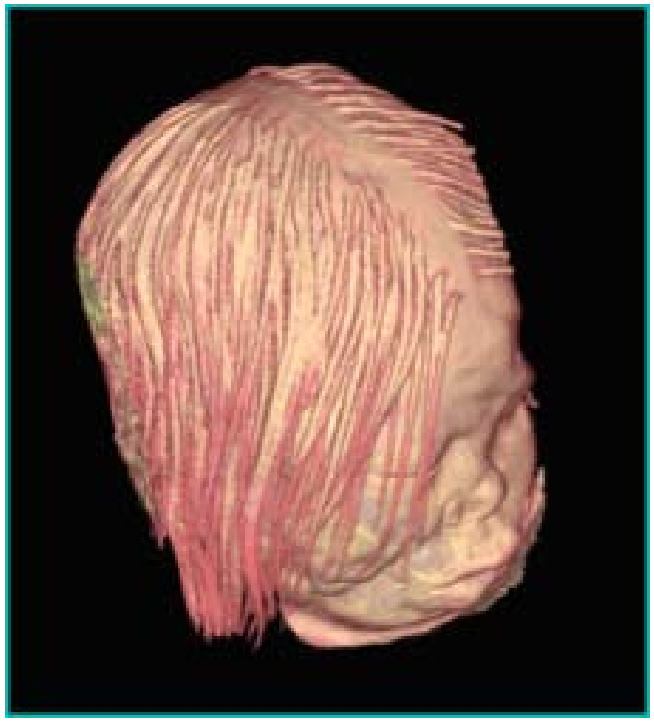

Figura 4. Reconstrucción VRT del rostro.
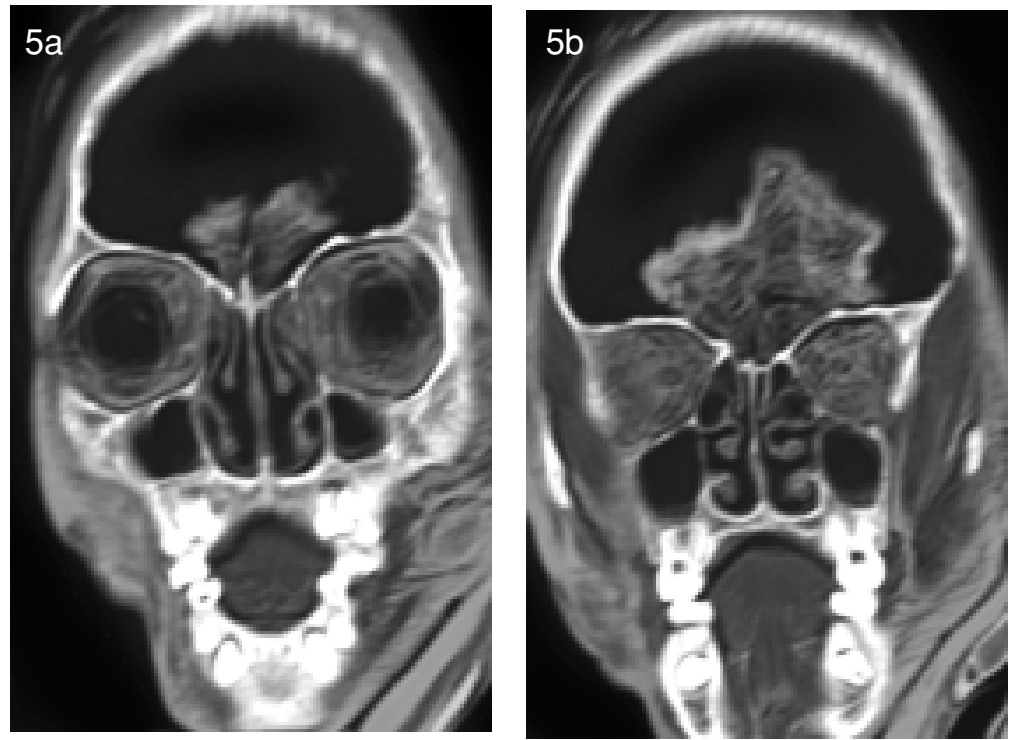

Figura 5 a, b. Reconstrucciones coronales a la altura de las órbitas (a) y cavidades paranasales (b). 


\section{Resultados}

Posición: El niño se encuentra en posición fetal, recostado sobre su lado derecho, con flexión cervical y rotación de la cabeza a la derecha, apoyando el mentón sobre el esternón. El dorso, las caderas y las rodillas están flectadas, con piernas cruzadas. Los antebrazos se apoyan sobre las extremidades inferiores (Figura 2).

Cráneo y encéfalo: El cráneo no presenta signos de deformación ni trauma, las suturas se observan normales. El encéfalo presenta disminución global de sus dimensiones, lográndose diferenciar adecuadamente sustancia blanca de sustancia gris, y cuerpo calloso. No hay evidencia de alteraciones focales, malformación, ni traumatismos. No se observan signos de alteración de los compartimentos ventriculares, los que son amplios posiblemente por deshidratación del parénquima encefálico. El cerebelo y los elementos de fosa posterior se encuentran bien conservados, con menor grado de disminución de volumen relativo que el cerebro. Las amígdalas cerebelosas descienden a través del agujero magno aproximadamente $6 \mathrm{~mm}$. Hay gas ocupando el espacio que rodea al encéfalo. La duramadre se observa desprendida parcialmente y es posible identificar los senos transverso, sigmoideo y sagital superior (Figura 3).

Macizo facial: Se aprecia normal, sin evidencias de trauma. Huesos temporales neumatizados en forma simétrica, sin alteraciones del laberinto óseo. Canales semicirculares, cajas acústicas y conductos auditivos internos y externos sin evidencias de malformación, trauma ni procesos inflamatorios ni tumorales.

Buen estado general de huesos faciales, con adecuada neumatización de las cavidades paranasales. Hay incipiente desarrollo del seno esfenoidal, no observándose desarrollo del seno frontal. El revestimiento mucoso sinusal basal del seno maxilar izquierdo se aprecia despegado del piso óseo. El contenido orbitario es fácilmente identificable con globos oculares parcialmente colapsados, cristalinos en su posición normal y músculos extraoculares y nervios ópticos de aspecto conservado (Figuras 4, 5).

Análisis odontológico: En el maxilar superior se observan gérmenes de piezas 1 y 16 con calcificación coronaria iniciada. Piezas 2, 4, 5, 6, 11, 12,13 y 15 en evolución intraósea. Piezas 7, 8, 9 y 10 con cierre apical incompleto. Pieza 10 con leve falta de espacio, en posición palatina. En el maxilar inferior se observan gérmenes de piezas 17 y 32 , con calcificación coronaria iniciada. Piezas 18, 20, 21, 22, 27, 28, 29 y 31 en evolución intraósea. Piezas 19 y 30 con cierre apical incompleto. Piezas 23 a 26 con apiñamiento por leve falta de espacio. No se observan caries ni atrición (Figura 6).
El grado de desarrollo de las piezas dentarias corresponde a una edad cronológica de $8+/-1$ año.

Columna vertebral: La unión cráneo-cervical es normal, sin evidencias de trauma o malformación. Los cuerpos de las vértebras cervicales, dorsales y lumbares son de número, altura y alineamiento normales, sin malformaciones, trauma ni desviaciones patológicas. Los espacios intervertebrales se encuentran disminuidos de altura debido a deshidratación discal y la mayoría de ellos presentan gas. En el espacio L1-L2 existe además una pequeña calcificación redondeada de $4 \mathrm{~mm}$. No se observan masas paravertebrales. El canal raquídeo y su contenido son normales, identificándose la médula en toda su extensión. El cono medular se encuentra a la altura de T12-L1. También son identificables la duramadre y algunas raíces nerviosas (Figura 7).

Extremidades: Los huesos largos presentan configuración normal. Hay gas en todos los espacios articulares y en algunas vainas tendíneas. Las extremidades superiores e inferiores presentan musculatura bien conservada, sin alteraciones evidentes. El tejido muscular se encuentra infiltrado por gas, lo que disminuye notablemente su densidad en TC respecto al tejido vivo. No se identifican lesiones óseas, tumorales, inflamatorias, ni líneas de Park-Harris (Figura 8).

Tórax: El esófago presenta un trayecto normal, dilatado hasta $2.4 \mathrm{~cm}$ y con abundante contenido sólido desde la orofaringe hasta la unión gastroesofágica. Aorta parcialmente colapsada, en situación habitual. Vena cava superior y venas innominadas de trayecto y calibre normales distendidas. Arteria pulmonar sin alteraciones a nivel del tronco y ramas principales. Corazón de cuatro cámaras, sin defectos septales evidentes y con pericardio visible. Los pulmones están colapsados, observándose los tres bronquios lobares derechos y los dos izquierdos permeables. El espacio pleural está ocupado por gas. El diafragma es continuo y no hay evidencia de hernia hiatal. Costillas de adecuado desarrollo, sin lesiones evidentes.

En el celular subcutáneo de ambas axilas se observan imágenes ovaladas, hipodensas y de centro graso, compatibles con linfonodos. Hay al menos cuatro a la derecha y cinco a la izquierda, y el mayor alcanza los $2.1 \mathrm{~cm}$ de diámetro (Figura 9).

Abdomen y pelvis: El abdomen se encuentra ocupado por abundante gas, levemente excavado, sin masas evidentes. El hígado se observa disminuido de volumen globalmente, sin lesiones. Venas suprahepáticas y porta presentes, de calibre normal. La vesícula está colapsada.

Las estructuras retroperitoneales se observan marcadamente disminuidas de volumen y mal delimitadas, el páncreas es parcialmente visible y los riñones presentan parénquima muy adelgazado. 


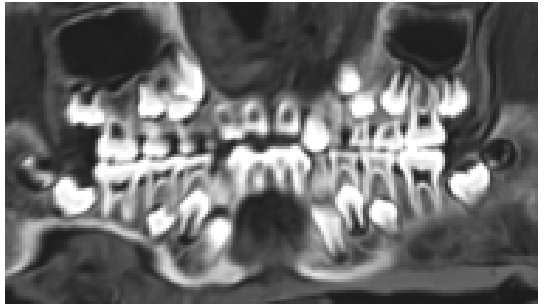

Figura 6. Reconstrucción curva de la dentadura, permite también estimar edad odontológica.

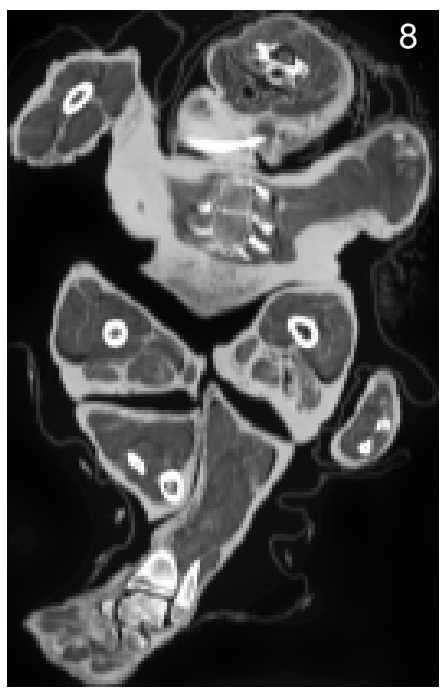

Figura 8. Corte a través del cuello, las extremidades superiores $e$ inferiores, lo que permite evaluar el sistema muscular y el celular subcutáneo.

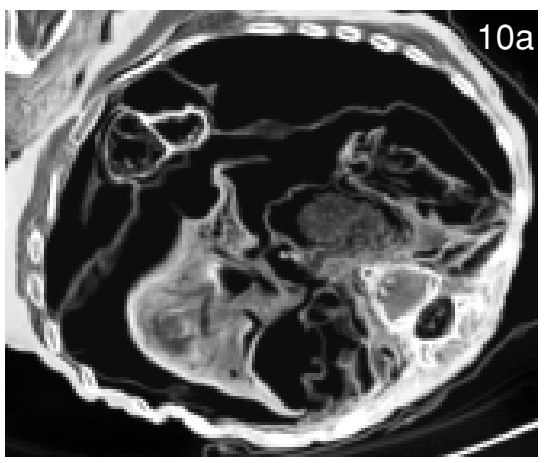

Figura 7 a, $b$. Reconstrucciones sagitales (a) $y$ coronales (b) de la columna vertebral.
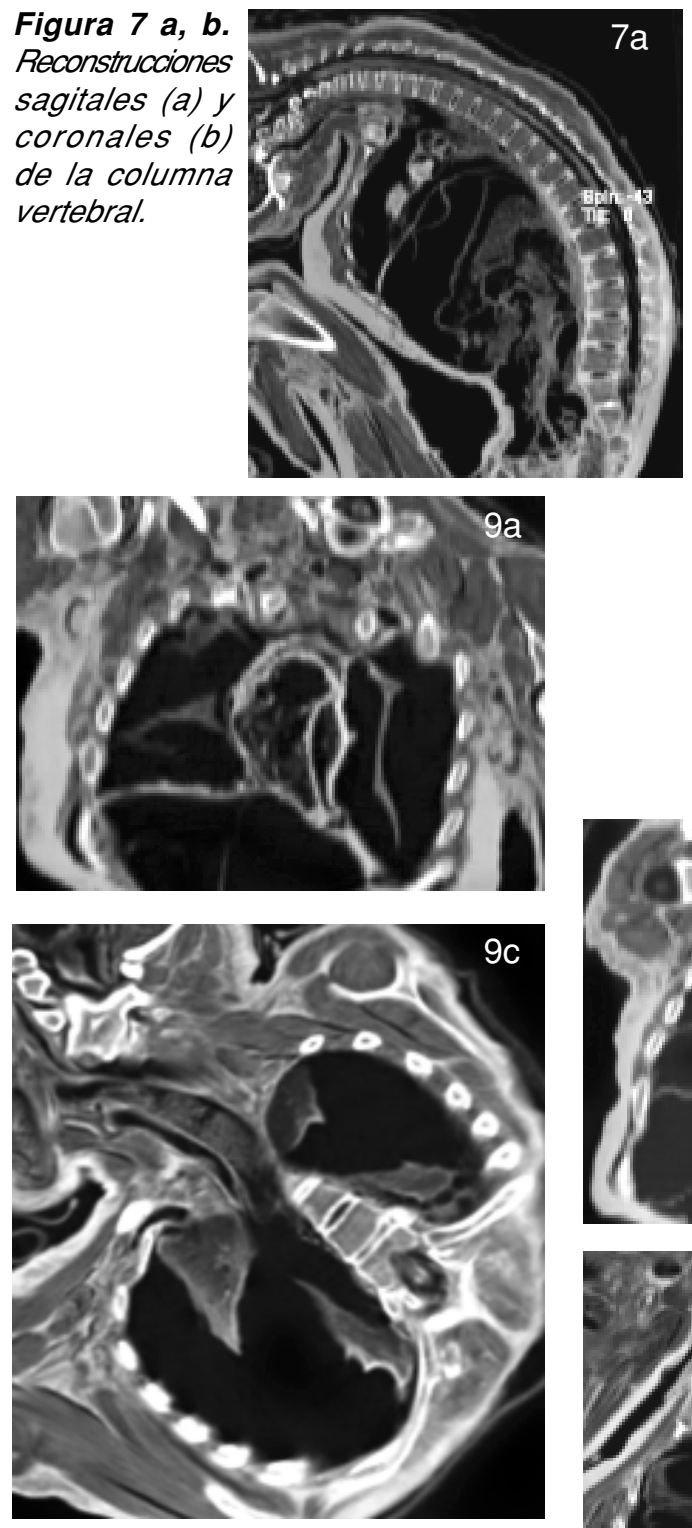

Figura 9 a-d. Reconstrucciones coronales y oblicuas que permiten evaluar el tórax y los órganos intratorácicos.
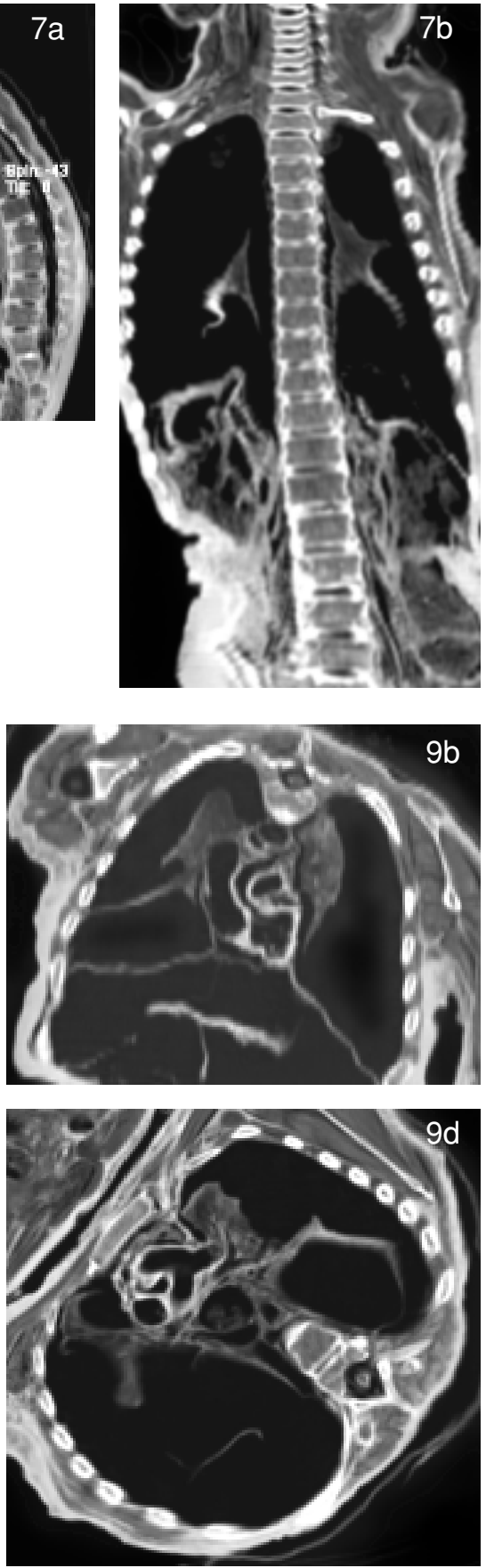
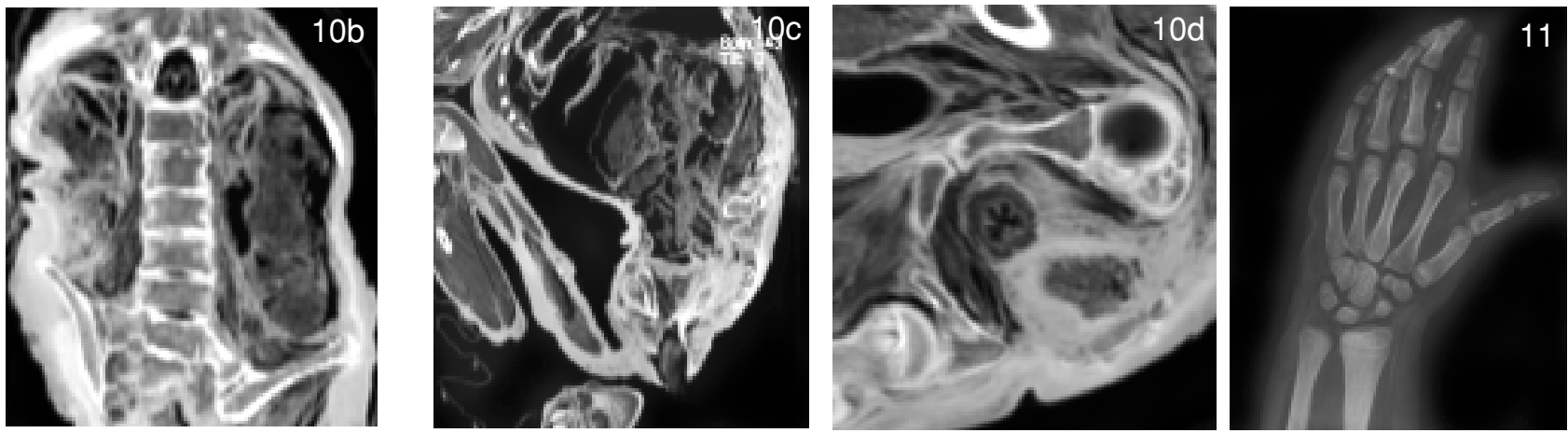

Figura 10 a-d. Reconstrucciones coronales (a), axiales (b), sagitales (c) y oblicuas (d) que permiten evaluar los órganos abdominales y pélvicos.

Figura 11. Radiografía de mano tomada en 1954. 
No se logran visualizar el bazo, la aorta abdominal, ni la vena cava inferior.

El estómago está distendido, con abundante contenido sólido. Colon transverso, descendente y sigmoides, y recto de pared fina y bien definida, de calibre normal y con abundante contenido sólido. El contenido fecal del recto sale al exterior a través del ano, el que se observa dilatado. No se definen claramente el colon ascendente ni el intestino delgado. La vejiga está colapsada, se logran identificar claramente mucosa, muscular y serosa. Los testículos están bien situados, parcialmente colapsados. El escroto es de grosor normal y el pene no presenta alteraciones. No se identifica la próstata. Las regiones inguinales no presentan alteraciones evidentes (Figura 10).

Piel y celular subcutáneo: El tejido celular subcutáneo se observa preservado y su espesor impresiona normal. Presenta leve aumento de su densidad tomográfica respecto al tejido vivo.

Radiografías de manos: La edad ósea estimada en base a las radiografía de mano, según el atlas de Greulich y Pyle, es de 8 años (Figura 11).

\section{Discusión}

El estudio radiológico de momias lo inician Konig, Holland y Dedekind en 1896, sólo unos meses después del descubrimiento de los rayos $X$ por Roentgen, ya que éstos brindaron la posibilidad de estudiarlas con un método objetivo, no invasivo, que permite determinar caracteres antropométricos, sexo, edad cronológica, estado nutricional, evaluar órganos internos e identificar secuelas de enfermedades y eventos relacionados con la muerte, sin necesidad de necropsia.

A partir de esa fecha se ha publicado gran número de libros y artículos que describen técnicas de estudio y hallazgos paleoradiológicos en momias.

En América del Sur también se han estudiado imagenológicamente las momias de indoamericanos, siendo el estudio radiográfico convencional realizado a este niño en 1954 uno de los primeros reportados. Otros estudios similares se realizaron a dos hombres incas, uno del cerro El Toro (1966) y otro del cerro Aconcagua (1985) y a una mujer inca del cerro de Ampato (1995). Más recientemente un equipo argentino publicó el estudio de las momias de Llullaillaco, que se encontraban en excelente estado de preservación, con tomografía computada convencional (TC). Estos estudios han incluido sólo radiografías o TC convencional. En nuestro caso utilizamos TC-M, la cual brinda sustanciales ventajas.

La radiografía convencional al atravesar un objeto tridimensional genera una imagen en dos planos, lo que superpone estructuras y no permite estudiar adecuadamente los tejidos blandos debido a la baja resolución de contraste. Sin embargo, es de gran utilidad en el estudio esquelético y dental, permitiendo evaluar mineralización y desarrollo óseos, cálculo de edad ósea, edad odontológica, y presencia de lesiones traumáticas o enfermedades óseas y articulares. Sus ventajas incluyen: bajo costo, amplia disponibilidad, y portabilidad en algunos casos. Al ser una técnica bidimensional su utilidad se ve limitada en momias en posición fetal o rodeadas de otros objetos, ya que es difícil lograr la desproyección adecuada del segmento anatómico que se desea estudiar.

En la TC las imágenes son generadas a través de complejos sistemas de reconstrucción y son de gran fidelidad morfológica y diagnóstica. Es la técnica ideal para el estudio de momias, ya que gracias a su alta resolución espacial y de contraste, además de estudiar el esqueleto, permite obtener información tanto de los tejidos blandos como de los órganos internos.

El advenimiento de la técnica multicorte hizo posible adquirir imágenes de un objeto en forma volumétrica, no dejando áreas sin estudiar. El desarrollo de programas de post-proceso permite además reconstruir imágenes digitales en todos los planos del espacio. Esto hace posible el estudio detallado de momias, creando modelos tridimensionales y reconstrucciones de su apariencia física original. Los estudios endocavitarios virtuales que se han desarrollado gracias a ella, como lo es la broncoscopía virtual, también se han empleado en las momias. Dados estos avances, algunos han denominado «Antropología virtual» a esta nueva modalidad paleoradiológica.

Otro beneficio de esta técnica es obtener muestras de tejidos a través de punciones guiadas por TC, lo que permite una mejor orientación hacia el órgano al cual se quiere acceder, preservando la integridad física de los cadáveres.

Los equipos de ultrasonido y resonancia magnética utilizados en medicina requieren de la presencia de agua en los tejidos, lo que limita su uso en cadáveres momificados, ya que generan imágenes de muy mala calidad. La ultrasonografía además se ve limitada por que la presencia de aire y material de momificación en los tejidos, obstaculizando la transmisión del haz de ultrasonido.

La momia por nosotros estudiada muestra que todos los órganos internos presentan grados variables de disminución de volumen por deshidratación, siendo los sistemas nervioso central y musculoesquelético los mejor conservados. Así mismo es posible identificar y caracterizar los órganos torácicos y en menor grado los abdominales.

La orofaringe, el esófago y el estómago presentan moderada cantidad de contenido sólido de origen alimentario. Fue posible observar también la presencia de material fecal en el recto y región 
interglútea, lo que hace plantear la posibilidad de que el niño hubiese vomitado y defecado en los momentos previos a su muerte.

El esqueleto se encuentra en excelente estado de conservación, lo que se asocia a adecuada preservación del sistema muscular y del celular subcutáneo, que impresionan normales tanto en volumen como en morfología. Ello permite deducir un adecuado estado nutricional al momento de la muerte.

El tejido adiposo subcutáneo y la sustancia blanca presentan mayor densidad tomográfica que en tejidos vivos, lo que se considera secundario a la transformación en adipocira.

Llamó la atención la presencia de múltiples imágenes de linfonodos axilares que hipotéticamente podrían estar en relación a la presencia de alguna enfermedad infecciosa o parasitaria. Sin embargo, no se puede descartar que se trate de linfonodos normales que se han hecho más evidentes después de la muerte.

El descenso de las amígdalas cerebelosas es llamativo, dado que persiste a pesar de la disminución de volumen del encéfalo. Ello nos hace considerar la posibilidad de que el niño fuera portador de una malformación de Chiari I asintomática. Dicho hallazgo también pudo deberse a un aumento agudo de la presión intracraneana secundario a edema cerebral de altura.

Las edades ósea y dental son coincidentes.

\section{Conclusiones}

El grosor del panículo adiposo y el desarrollo esquelético sugieren un adecuado estado nutricional, y permiten inferir también que se trataba de un niño de 8 años en buen estado general de salud.

La presencia de linfonodos axilares, el descenso de las amígdalas cerebelosas y el contenido esofágico gástrico e intestinal identificados con TC-M plantean nuevas interrogantes para futuras investigaciones.
No se identificaron lesiones traumáticas que pudieran relacionarse con su muerte.

La TC-M demostró ser una herramienta de extraordinaria utilidad en el estudio de la momia del niño del cerro El Plomo, caracterizándola con gran detalle, sin dañar su integridad y permitiéndonos conocer más sobre su vida y su muerte.

\section{Bibliografía}

1. Cesarani F, Martina MC, Ferraris A et al. Wholebody three-dimensional multidetector CT of 13 Egyptian human mummies. AJR Am J Roentgenol 2003; 180: 597-606.

2. Chhem RK, Ruhli FJ. Paleoradiology: Current status and future challenges. Can Assoc Radiol J 2004; 55: 198-199.

3. Greulich WW, Pyle SI. Radiographic atlas of skeletal development of hand and wrist. Second Edition, 1959. Stanford University Press.

4. Harris JE, Wente EF. An x-Ray atlas of the royal mummies. The University of Chicago, 1980.

5. Murphy WA Jr, Zur Nedden D, Gostner P, et al. The iceman: Discovery and imaging. Radiology 2003; 226: 614-629.

6. Previgliano $\mathrm{CH}$, Ceruti $\mathrm{C}$, Reinhard $\mathrm{J}$ et al. Radiologic evaluation of the Llullaillaco mummies. AJR Am J Roentgenol 2003; 181: 1473-1479.

7. Recheis W, Weber GW, Schafer K, et al. New methods and techniques in anthropology. Coll Antropol. 1999; 23: 495-510.

8. Ruhli FJ, Hodler J, Boni T. CT-guided biopsy: A new diagnostic method for paleopathological research. Am J Phys Anthropol. 2002; 117: 272-275.

9. Ruhli FJ, Chhem RK, Boni T. Diagnostic paleoradiology of mummified tissue: Interpretation and pitfalls. Can Assoc Radiol J 2004; 55: 218-227.

10. Thekkaniyil JK, Bishara SE, James MA. Dental and skeletal findings on an ancient Egyptian mummy. Am J Orthod Dentofacial Orthop. 2000; 117: 10-14. 